\title{
Volume Regulation in the Bovine Lens and Cataract The Involvement of Chloride Channels
}

Jin Jun Zhang and T.J.C. Jacob

Eye Research Lab, Physiology Unit, School of Molecular \& Medical Biosciences, University of Wales, Cardiff CF1 3US, United Kingdom

\begin{abstract}
The purpose of this study was to investigate volume regulation in the lens and its involvement in lens opacification (cataract) and the role of chloride channels in these processes. Single, isolated lens fiber cells from the lens were whole cell patch clamped. When exposed to hypotonic solution, an outwardly rectifying whole-cell current was activated. The current increased from 1.0 to $32.6 \mathrm{pA} / \mathrm{pF}$, reversed at the chloride reversal potential $\left(\mathrm{E}_{\mathrm{Cl}}=0 \mathrm{mV}\right)$, and was blocked by the chloride channel blockers 5, nitro-2-(3phenylpropylamino) benzoate (NPPB) and tamoxifen. Replacing all but $5 \mathrm{mM}$ of the external chloride with gluconate caused the reversal potential to shift $+33 \mathrm{mV}$, consistent with a $\mathrm{Cl}^{-}$current with a gluconate/chloride permeability ratio of 0.26 . When the whole lens of the eye was exposed to hypotonic solution, there was an initial increase in anteriorposterior diameter (5-8 $\mathrm{min}$ ), representing lens swelling of $6.5 \%$. This was followed by a decrease in volume to a new steady state value that lasted for up to $2 \mathrm{~h}$. In the longer term ( $\geq 2 \mathrm{~h})$, the lenses began to swell again. The simultaneous exposure to hypotonic solution and tamoxifen or NPPB caused swelling and prevented this volume regulation. Lenses incubated in hypotonic solution and hypotonic solution containing tamoxifen became opaque after a 2-h incubation period. We conclude that the lens is able to volume regulate. It possesses volume-activated $\mathrm{Cl}^{-}$channels, the inhibition of which results in inhibition of volume regulation, lens swelling and opacification. Our data suggest the longterm prophylactic use of tamoxifen may make the patient more susceptible to cataract. (J. Clin. Invest. 1996. 97:971978.) Key words: tamoxifen $\bullet \mathrm{NPPB} \cdot \mathrm{Cl}^{-}$channel $\bullet$ regulatory volume decrease $\bullet$ ion channels
\end{abstract}

\section{Introduction}

Clinically and experimentally, it has long been known that osmotic changes are associated with lens opacification and cataract. The lens swells $(1,2)$ and opacifies (3) when exposed to hypotonic solution, and this is accompanied with an increase in membrane permeability (4) and volume regulation (2). An increase in membrane permeability (5) and decrease in membrane potential (6) as a function of age have been observed in

Address correspondence to Dr. T. Jacob, Eye Research Lab, POB 911, University of Wales, Cardiff, CF1 3US, UK. Phone: 44-1222874105; FAX: 44-1222-874094; E-mail: jacob@cardiff.ac.uk

Received for publication 10 August 1995 and accepted in revised form 4 December 1995.

J. Clin. Invest.

(C) The American Society for Clinical Investigation, Inc.

0021-9738/96/02/0971/08 \$2.00

Volume 97, Number 4, February 1996, 971-978 human lenses. Lens swelling is associated with opacification in many different experimental conditions, for example, inhibition of $\mathrm{Na}^{+} / \mathrm{K}^{+} /$ATPase pumps either by cooling or with ouabain (7-9) and exposure to hypertonic sugar solutions (10). In several different types of genetic cataract, for example Nakano and Philly cataract in mice, the fiber cells swell, and there is increased lens hydration before opacification (11). In the human lens, cataract has been observed in patients with renal failure as a result of the osmotic effect of the increased blood urea (12), and transient opacities followed the abrupt changes to the urea levels that occur in dialysis (13). Harding (14) has suggested that the uremia provoked by severe diarrhea could partly explain the high prevalence of cataract in some tropical countries. Lens swelling underlies the refractive index changes that are observed in diabetics in response to changes in glucose levels in plasma (15-17). Jacob and Duncan (4) demonstrated that the increase in lens membrane permeability, which accompanies lens swelling, occurred even when raised levels of glucose were presented isoosmotically. Glucose can enter the lens via facilitated diffusion, and upon entry it exerts an osmotic swelling pressure. The link between lens swelling and cataract is necessarily indirect in the human lens because of the difficulty of measuring lens diameter accurately in situ, and because the myopic shift which occurs during cataract may obscure any underlying swelling-induced myopia, although it is entirely possible that the myopic shift, which is the symptom that first brings many cataract sufferers to the optician, is a direct result of lens swelling. However, support for the link also comes from the observed loss of accomodation before cataract in patients who would, by virtue of their youth, still be expected to have accommodative power (18).

We have previously reported the presence of chloride channels in the lens $(19,20)$ and that chloride channels contribute to anterior and posterior potentials in the lens (21). In this study, we demonstrate that the $\mathrm{Cl}^{-}$channels in the lens are volume activated and are associated with the volume-regulatory response after exposure to hypotonic media.

\section{Methods}

Isolation of single-fiber cells. Bovine eyes were obtained from a local abattoir $\sim 2 \mathrm{~h}$ post mortem. Lenses were dissected, and the capsule with epithelium was removed by making an incision on the anterior surface with fine scissors and peeling it off with forceps. A posterior portion of the remaining lens was dissected, washed twice with artificial aqueous humour $(\mathrm{AAH})^{1}$ to remove any adhering epithelial cells, and placed in a tube containing $0.25 \%$ trypsin and $0.02 \%$ EDTA in a $\mathrm{Ca}^{2+} / \mathrm{Mg}^{2+}$ free buffer for $18 \mathrm{~min}$ in a shaking water bath at $37^{\circ} \mathrm{C}$. Medium E199 (Sigma, Poole, UK) $+10 \%$ fetal calf serum was added to

1. Abbreviations used in this paper: $\mathrm{AAH}$, artificial aqueous humor; a-p, anterior-posterior; NMDG, $N$-methyl-D-glucamine chloride; NPPB, 5, nitro-2-(3-phenylpropylamino)benzoate. 
stop the trypsin digestion. The incubation mixture was then shaken the upper portion was pipetted into a centrifuge tube, and the cells were centrifuged at $1,000 \mathrm{rpm}$ for $5 \mathrm{~min}$. The supernatant was discarded, the pellet was washed with AAH and recentrifuged, and the supernatant was discarded again. Medium E199 + serum (1 ml) was added and the top layer of cells was removed and plated onto agar. In this manner, small, viable fiber cells containing nuclei were obtained. The cells were plated onto agar as follows: Agar was heated to boiling and allowed to cool to $\sim 45-50^{\circ} \mathrm{C}$, at which point a coverslip was dipped into the agar. The coverslip thus coated with agar was placed into a Petri dish, and cells were added to the agar.

The cells prepared in this manner were not epithelial cells. First, the capsule and epithelium were removed, and every effort was made to remove any remaining epithelial cells; second, they were obtained from a posterior, cortical portion of the lens; third, they had polymorphous nuclei, unlike epithelial cells, which have round nuclei, and fourth, unlike epithelial cells, they did not grow in culture. The surface of these cells was covered with membrane processes distinguishing them from fiber cell vesicles, which are usually smooth under the light microscope. The cells are probably recently differentiated fiber cells from a cortical region of the lens.

Solutions. In whole-cell patch-clamp experiments, the pipette contained the following (in $\mathrm{mM}$ ): $N$-methyl-D-glucamine chloride (NMDG-Cl), 105; $\mathrm{MgCl}_{2}$, 1.2; D-mannitol, 70; Hepes, 10; EGTA, 1; and ATP, 2. The $\mathrm{pH}$ was adjusted to 7.2 with Trizma base. The bath contained mannitol-AAH composed of the following (in $\mathrm{mM}$ ): $\mathrm{NaCl}$, $105 ; \mathrm{MgCl}_{2}, 0.5 ; \mathrm{CaCl}_{2}, 2$; D-mannitol, 70; and Hepes, 10. The $\mathrm{pH}$ was adjusted to $\mathrm{pH} 7.4$ with Trizma base. To obtain hypotonic bath solutions, the D-mannitol was removed. The whole lenses were incubated in $\mathrm{AAH}$, which had the following composition (in $\mathrm{mM}$ ): $\mathrm{NaCl}, 125$; $\mathrm{KCl}, 4.5 ; \mathrm{NaHCO}_{3}, 10 ; \mathrm{CaCl}_{2}, 2 ; \mathrm{MgCl}_{2}, 0.5$; glucose, 5; sucrose, 20; and Hepes, 10. The $\mathrm{pH}$ was adjusted to 7.4 with $3 \mathrm{M} \mathrm{NaOH}$. Hypotonic solutions for whole-lens incubation experiments were obtained either by $50 \%$ dilution of AAH with distilled water (Figs. 3 and 4) or by removing the appropriate amount of mannitol from the mannitol$\mathrm{AAH}$, the composition of which is given above: $70 \mathrm{mM}$ mannitol (control), $58.7 \mathrm{mM}$ (4.7\% hypo), $46.7 \mathrm{mM}$ (9.4\% hypo), $23.3 \mathrm{mM}$ (18.7\% hypo), $0 \mathrm{mM}$ ( $25 \%$ hypo). These solutions were used for the experiments shown in Figs. 5 and 6.

5, Nitro-2-(3-phenylpropylamino) benzoate (NPPB) was a gift from SmithKline Beecham (Welwyn, Herts, UK). All other chemicals were obtained from Sigma unless otherwise stated.

Patch-clamp and whole-cell clamp recording. The patch-clamp recording methods have been described in detail previously (20). Whole-cell currents were recorded using a patch clamp amplifier (8900; Dagan Corp., Minneapolis, MN). Recording electrodes were pulled from borosilicate glass capillaries (Clark Electromedical, Reading, UK) using a two-stage vertical pipette puller (Narashige PB-7, Tokyo, Japan) and were fire polished to a resistance of 4-8M $\Omega$ when filled with the NMDG-Cl pipette solution. The bath electrode consisted of an $\mathrm{Ag}-\mathrm{AgCl}$ pellet connected to the bathing solution via an agar bridge made up in normal pipette solution. Liquid junction potentials were measured with the electrode in the bath, and, if they were $>1 \mathrm{mV}$, the appropriate adjustment was made. Voltage and current signals from the amplifier together with synchronizing pulses were digitized using an interface (1401; Cambridge Electronic Design, Cambridge, UK) and recorded on computer disks using a PC computer. The voltage pulse generation and voltage clamp analysis were achieved by using the EPC patch and voltage clamp software (version 6.0; Cambridge Electronic Design).

Some of the current data are expressed in terms of $\mathrm{pA} / \mathrm{pF}$. The capacitance of the fiber cells was determined from the time constant of the decay of the capacititative transient after a small voltage clamp step. The decay was fitted with a single exponential, the series resistance was calculated from the peak of the capacitative transient $\left(R_{\mathrm{s}}=\right.$ $I / V)$, and the capacitance was determined from $C=\tau / R_{\mathrm{s}}$. The mean capacitance $( \pm \mathrm{SE})$ was found to be $14.0 \pm 6.4 \mathrm{pF}(n=5$, range 3.0 $41.5 \mathrm{pF}$ ), and the series resistance was $58.8 \pm 0.6 \mathrm{M} \Omega$.
Lens diameter measurements. Lenses were placed in rectangular boxes made from optically clear glass and photographed from the side using a digital camera (EDC-1000; Electrim Corp., Princeton, $\mathrm{NJ}$ ). The images were measured using image processing software (IPSHR; Mnemonics, Mt. Laurel, NJ). The anterior-posterior (a-p) diameter was found to change, whereas the equatorial diameter did not change significantly during any of the experimental maneuvers; for instance, in $50 \%$ hypotonic solution, the normalized a-p diameter increased from 1.00 to $1.07 \pm 0.02$, whereas the equatorial diameter did not increase significantly; $1.01 \pm 0.01$ (mean $\pm \mathrm{SE} ; n=3$ ) after $210 \mathrm{~min}$. Therefore, only the a-p diameter (or volume) is referred to in the rest of this report. Experiments were performed at room temperature unless otherwise indicated.

The lens volume, calculated from the mean a-p $\left(r_{1}=11.8 \pm 0.3\right.$ $\mathrm{mm})$ and equatorial $\left(r_{2}=18.5 \pm 0.3 \mathrm{~mm}\right)$ diameters using the formula volume $=4 / 3 \pi\left[\left(r_{1}+r_{2}\right) / 2\right]^{3}$ was $1,833 \pm 81 \mu l(n=14)$.

The effects of hypotonic solution at $24^{\circ} \mathrm{C}$ and $35^{\circ} \mathrm{C}$ were not significantly different; after $60 \mathrm{~min}$ the lens diameter (normalized) had increased to $1.031 \pm 0.013\left(\right.$ mean $\pm \mathrm{SE} ; n=3$ ) at $24^{\circ} \mathrm{C}$ and to $1.022 \pm 0.005$ at $35^{\circ} \mathrm{C}(n=5)$.

All measurements are given as mean \pm SE unless otherwise stated.

Lens transparency measurements. Lenses were placed into a Petri dish, illuminated with a ring fluorescent tube, and photographed from above against a dark background with a digital camera (EDC-1000). The images were analyzed using software (IMDISP) from R. Baalke (Jet Propulsion Lab Pasadena, CA; IMDISP was written by M. Martin, F. Evans, and D. Nakamura of the Jet Propulsion Lab).

\section{Results}

Single-cell studies. Single isolated fiber cells, obtained from the most superficial cortical region of the posterior lens, were recorded from using the whole-cell patch-clamp technique with NMDG-Cl in the pipette to eliminate potassium currents. The cell was held at $0 \mathrm{mV}$, the reversal potential for chloride, and stepped to $\pm 40,80 \mathrm{mV}$. The reversal potentials for calcium and sodium were infinitely positive since the pipette did not contain either of these ions and neither the bath nor the pipette contained potassium. When a fiber cell was exposed to a solution made $25 \%$ hypotonic by removal of D-mannitol, the whole-cell current (measured at a $80 \mathrm{mV}$ voltage step) increased from $20.1 \pm 4.9 \mathrm{pA}(n=4)$ to $456.6 \pm 113.8 \mathrm{pA}$. However, the capacitance did not change; it was $19.5 \pm 9.3 \mathrm{pF}$ in control and $14.0 \pm 6.4 \mathrm{pF}$ in hypotonic solution. This was observed in 13 cells; a representative example is given in Fig. 1. Generally, the current increase was irreversible during these experiments. Fig. $1 A$ illustrates the voltage clamp current transients in response to the above voltage protocol, and the steady-state values of these currents (measured at $100 \mathrm{~ms}$ ) are plotted as a function of time in Fig. $1 \mathrm{~B}$. The current exhibited outward rectification and reversed at the chloride equilibrium potential. Replacing all but $5 \mathrm{mM}$ of the external $\mathrm{Cl}^{-}$with gluconate caused a shift in the reversal potential of $33.2 \pm 4.8 \mathrm{mV}$ $(n=8)$ (Fig. $1 C$ ). The plot of the logarithm of external $\mathrm{Cl}^{-}$ concentration against reversal potential deviated from the Nernst prediction (Fig. 1 C, dotted line) but could be fitted if a limited gluconate permeability was assumed. From a fit of Equation 1 to the data, a permeability ratio, $P_{\text {gluconate }} / P_{\mathrm{Cl}}$, of 0.26 was determined (Fig. $1 C$, solid line).

$E_{\mathrm{rev}}=R T / z F \log _{\mathrm{e}}\left[\mathrm{Cl}_{\mathrm{i}} /\left(C l_{\mathrm{o}}+p\right.\right.$. Gluconate $\left.\left._{\mathrm{o}}\right)\right]$

where $\mathrm{p}=\mathrm{P}_{\text {gluconate }} / \mathrm{P}_{\mathrm{Cl}} ; \mathrm{R}, \mathrm{T}, \mathrm{z}$, and $\mathrm{F}$ have their usual meanings; and the subscripts $i$ and $o$ refer to the internal and external ion concentrations, respectively. 
A

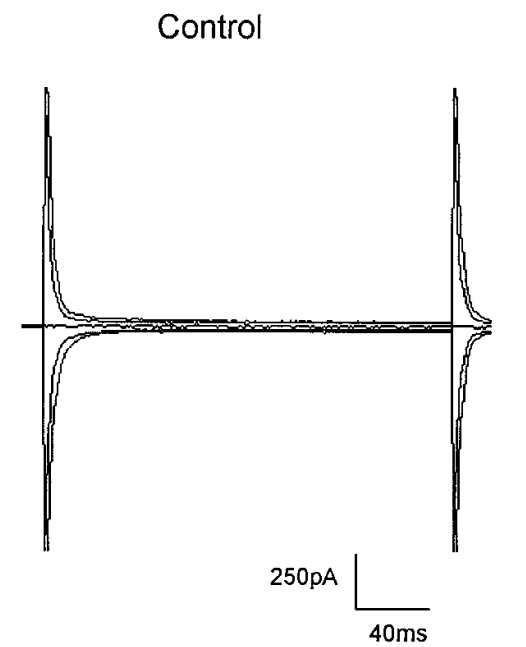

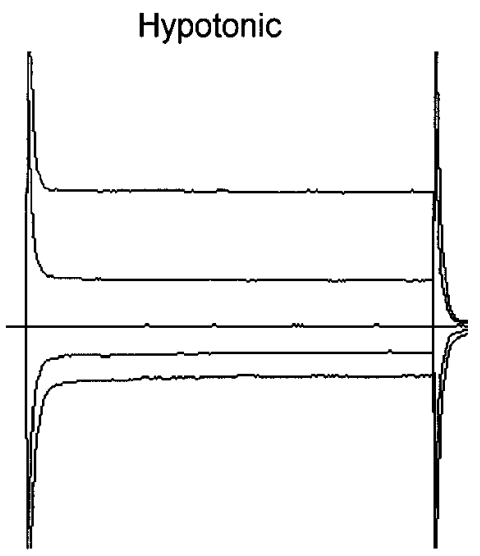
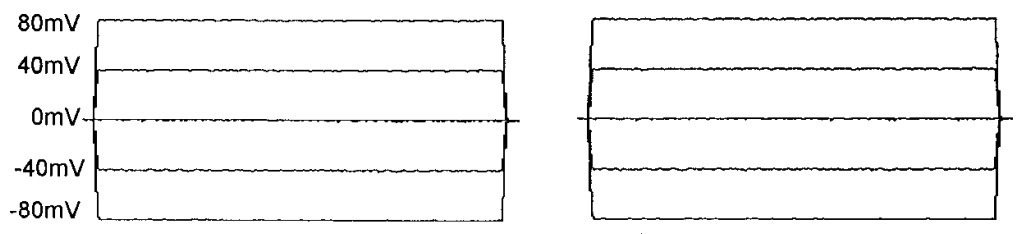

B
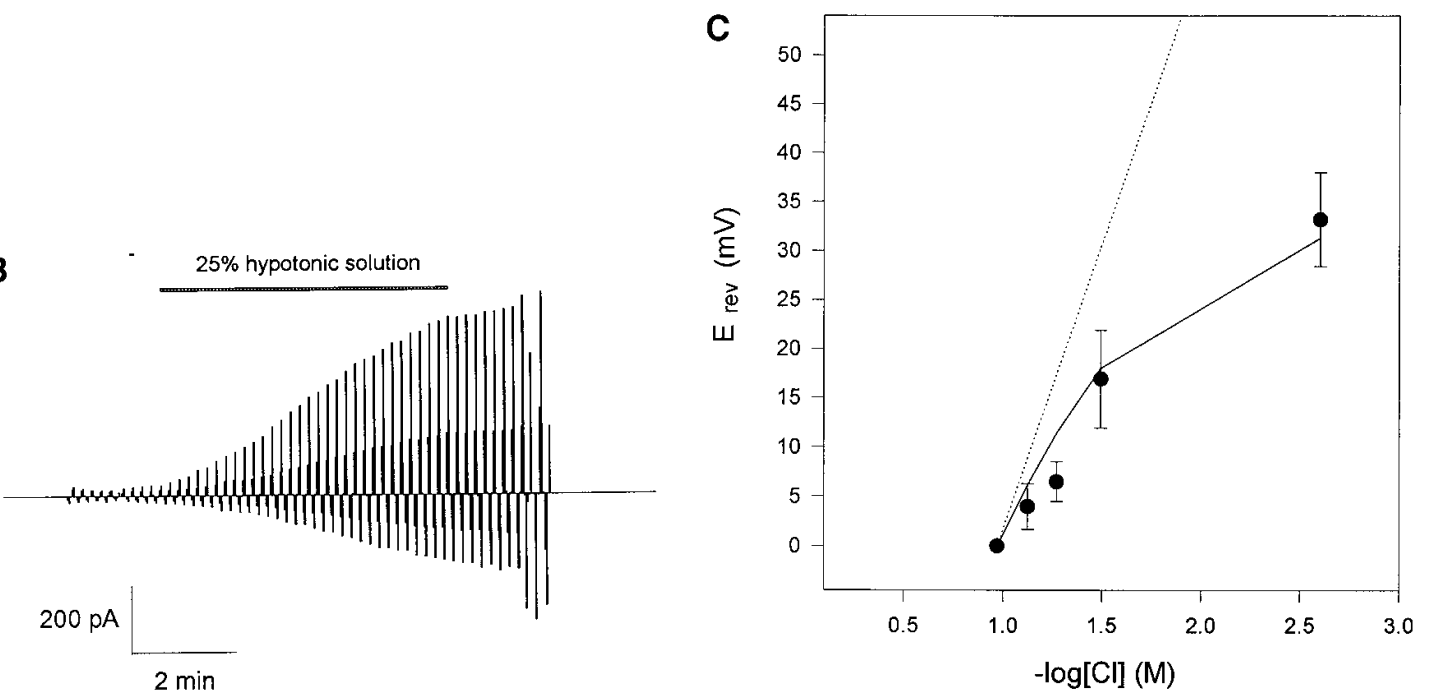

Figure 1. (A) Whole-cell recording from an isolated lens fiber cell. The cell was voltage clamped at $0 \mathrm{mV}$ and $200 \mathrm{~ms}$ voltage pulses of \pm 40 and $80 \mathrm{mV}$ were applied. The pipette contained an NMDG-Cl solution, and the bath contained mannitol-AAH (see Methods). The mannitol was removed to make the solution $25 \%$ hypotonic. During exposure to hypotonic solution, an outwardly rectifying current was activated that reversed at the reversal potential for chloride $\left(E_{\mathrm{Cl}}=0 \mathrm{mV}\right)$. A representative experiment from 13 is illustrated. $(B)$ The steady-state current value in response to the above voltage protocol was measured at $100 \mathrm{~ms}$ and is plotted against time. The current began increasing after exposure to hypotonic solution and was not reversible upon return to isotonic conditions in most cells. $(C)$ Dependency of the reversal potential $\left(E_{\text {rev }}\right)$ upon external $\left[\mathrm{Cl}^{-}\right]$. With symmetrical $\mathrm{Cl}^{-}$, the potential reversed at zero, and, as the external $\mathrm{Cl}^{-}$was replaced with gluconate, the reversal was shifted in the direction expected for a $\mathrm{Cl}^{-}$current. The shift was less than that predicted by the Nernst equation (dotted line); however, the amount of shift could be predicted if it was assumed that gluconate had a certain permeability through the $\mathrm{Cl}^{-}$channel. Using Equation 1, the data were fitted with a gluconate/chloride permeability ratio $(p)$ of 0.26 (solid line). The data represent the mean $\pm \mathrm{SE}$ (bars) of four cells. Experiments were performed at room temperature.

These initial experiments established the swelling-activated current as an outwardly rectifying chloride current.

This conclusion was confirmed by the block of the swellingactivated current by the $\mathrm{Cl}^{-}$channel blocker NPPB $(20 \mu \mathrm{M}$, Fig. 2). This block was reversible (not shown). The whole-cell current activated by hypotonic solution and the block of this current is given in Fig. $2 A$, and the degree of block is given in
Table I. NPPB causes a similar degree of block in both pigmented (22) and nonpigmented (23) ciliary epithelial cells. Tamoxifen has been reported to be a very specific inhibitor of the volume-activated chloride current in a number of cells (24), and it was found to block a chloride channel in lens fiber cells in excised inside-out patch-clamp experiments (20). Tamoxifen $(100 \mu \mathrm{M})$ caused a reversible block of the swelling- 
A

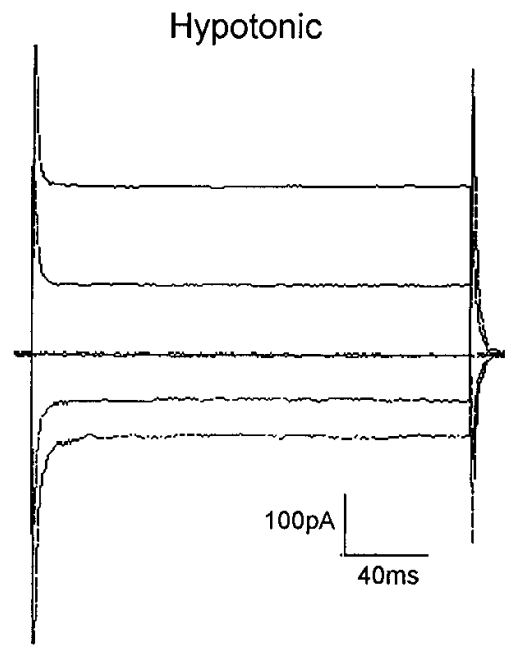

$80 \mathrm{mV}$

$40 \mathrm{mV}$

$-40 \mathrm{mV}$

$-80 \mathrm{mV}$

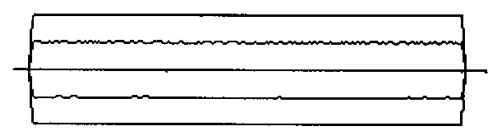

B

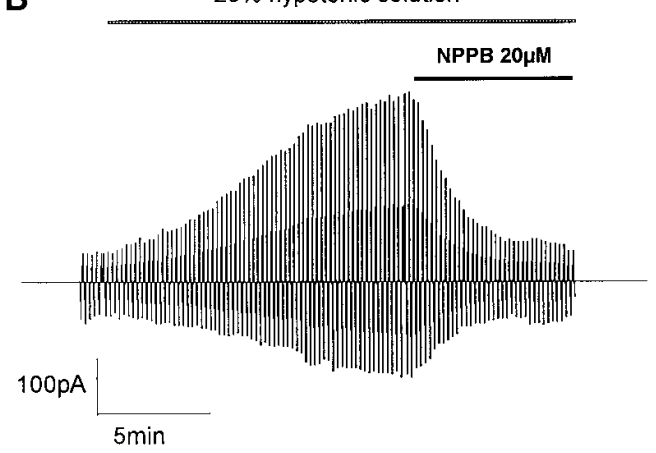

C

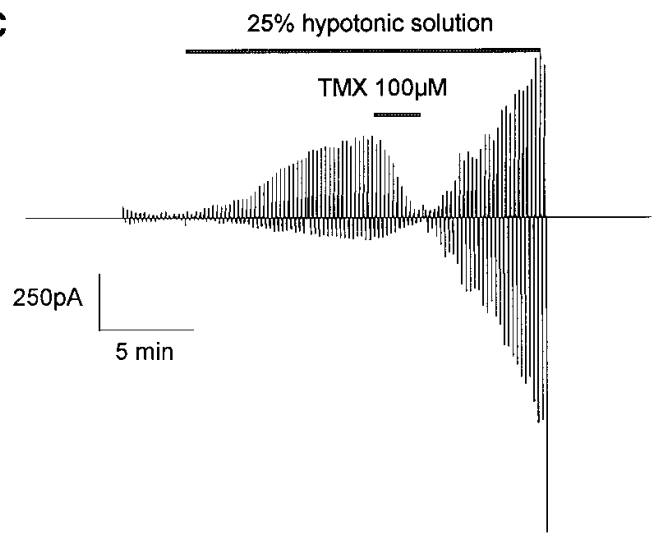

NPPB
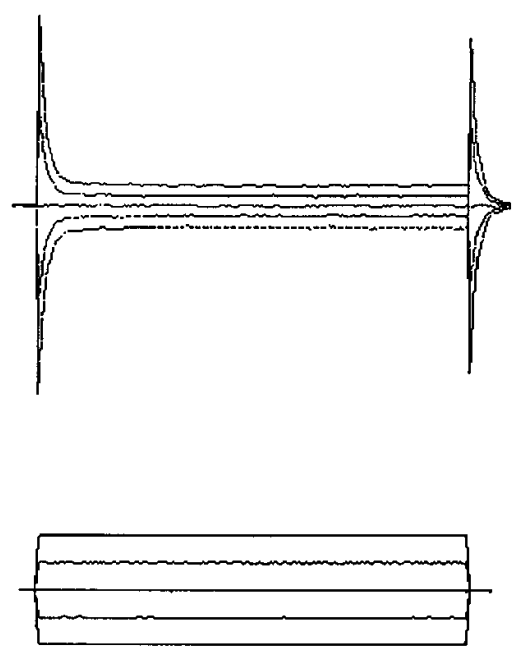

Figure 2. (A) The current activated by hypotonic solution was blocked by NPPB. On the left are the voltage clamp currents activated by exposure to hypotonic solution. The cell was held at $0 \mathrm{mV}$ and $200 \mathrm{~ms}$ voltage pulses of \pm 40 and 80 $\mathrm{mV}$ were applied. Addition of NPPB (20 $\mu \mathrm{M})$ caused a block of the swelling-activated chloride current (right-hand traces). The degree of block at each of the potentials is given in Table I. $(B)$ The steady-state current value in response to the above voltage protocol was measured at $100 \mathrm{~ms}$ and is plotted against time. The current began increasing after exposure to hypotonic solution and the addition of NPPB $(20 \mu \mathrm{M})$ caused a progressive, but reversible (not shown), decrease in the current. (C) The effect of tamoxifen (100 $\mu \mathrm{M})$ on the hypotonic-activated wholecell current. Voltage protocol was as for $A$. Tamoxifen caused a reversible block of the swelling-activated current in three experiments. The summary data for the blocking experiments with NPPB $(n=4)$ and tamoxifen $(n=3)$ are presented in Table I. The solutions were as described in Fig. 1, and all experiments were carried out at room temperature. activated current in these fiber cells (Fig. 2). The degree of block of tamoxifen is given in Table I.

These electrophysiological studies of lens fiber cells revealed a $\mathrm{Cl}^{-}$channel, activated by exposure to hypotonic solution, with characteristics that suggested it could contribute to volume regulation in the lens. We then examined the ability of the lens to volume regulate in the presence and absence of inhibitors of this channel.
Whole-lens studies. In this part of the study, we wished to test the ability of the lens to volume regulate when exposed to a hypotonic challenge and to examine whether such regulation could be interfered with by inhibitors of the volume-activated chloride current in the fiber cells.

In the initial whole-lens experiments, the lenses were exposed to AAH solution made $50 \%$ hypotonic by dilution with water and incubated at room temperature. We monitored the 
A

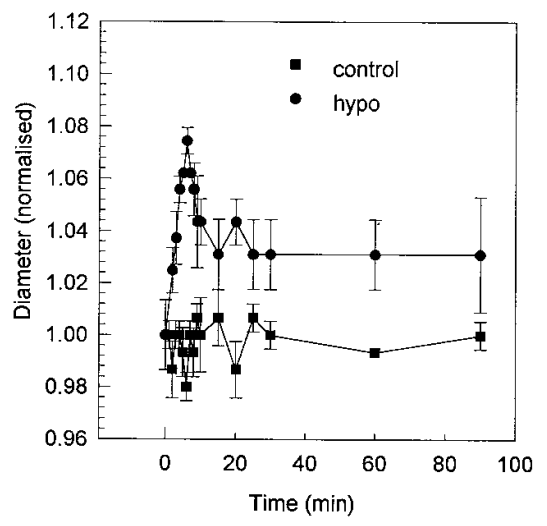

B

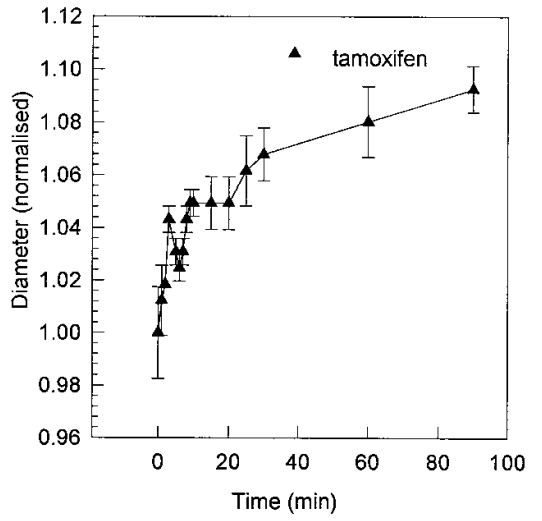

Figure 3. Lens a-p diameter in response to hypotonic solution. $(A)$ The lens a-p diameter was measured from digital images (see Methods) and normalized. The control lenses (squares) were incubated in AAH (see Methods) at room temperature. No significant change in their diameter was observed during the course of the experiment. Test lenses were exposed to AAH made 50\% hypotonic by dilution with water. In hypotonic solution (circles), there was an initial rise in lens diameter, to 1.073 within $6 \mathrm{~min}$, but thereafter the diameter decreased to 1.031 , where it remained until $100 \mathrm{~min}$. The effect on lens volume is given in the text. Data represent the mean \pm SE of three lenses in each case. $(B)$ In hypotonic solution with the presence of tamoxifen $(100 \mu \mathrm{M})$, the a-p diameter increased rapidly for the first $5 \mathrm{~min}$. After an attempt to volume regulate, the lens swelled progressively for the rest of the experiment. Data represent the mean $\pm \mathrm{SE}$ of three lenses. Experiments were carried out at room temperature. $a-p$ lens diameter as an index of lens swelling. The equatorial diameter did not change significantly in any of these experiments (see Methods). The $\mathrm{a}-\mathrm{p}$ diameter of bovine lenses increased $6 \%$ (from $11.37 \pm 0.07$ to $12.03 \pm 0.07 \mathrm{~mm}, n=3$ ) in the first $5 \mathrm{~min}$ exposure to hypotonic solution (Fig. $3 \mathrm{~A}$, circles). This represents a volume increase from $1,756 \pm 30 \mu l$ to $1,870 \pm 36 \mu \mathrm{l}(n=3)$; thereafter, the volume decreased to $1,790 \pm 40 \mu \mathrm{l}$, within $2 \%$ of the starting value after 16 min exposure to hypotonic solution. This implies that $80 \mu \mathrm{l}$ (or $\sim 4 \%$ of the total lens volume) of fluid was extruded during the $11 \mathrm{~min}$ it took for the lens to regulate its volume. The regulatory mechanisms maintain this volume for $\sim 100 \mathrm{~min}$, but thereafter the volume increases (not shown). Addition of tamoxifen $(100 \mu \mathrm{M})$ to the hypotonic solution prevents this volume regulation, and, after an initial biphasic response in the first $8 \mathrm{~min}$, the lenses swelled progressively (Fig. $3 \mathrm{~B}$ ). After $180 \mathrm{~min}$, the diameter had increased by $13 \%$ in tamoxifen (from $11.29 \pm 0.24$ to $12.75 \pm 0.12 \mathrm{~mm}, n=3$ ), representing a volume increase from $1,980 \pm 27 \mu$ l to $2,272 \pm 51 \mu \mathrm{l}$. Control lenses kept in isotonic solution maintain a relatively constant volume (Fig. $3 \mathrm{~A}$, squares).

Table I. The Effects of Blockers on the Volume-activated Current

\begin{tabular}{|c|c|c|c|c|}
\hline & \multicolumn{4}{|c|}{ Percent block } \\
\hline & $-80 \mathrm{mV}$ & $-40 \mathrm{mV}$ & $40 \mathrm{mV}$ & $80 \mathrm{mV}$ \\
\hline $\begin{array}{l}\mathrm{NPPB} \\
\quad(20 \mu \mathrm{M}, n=4)\end{array}$ & $41.5 \pm 19.5$ & $43.9 \pm 20$ & $64.5 \pm 12.5$ & $60.4 \pm 14$ \\
\hline $\begin{array}{l}\text { Tamoxifen } \\
\qquad(100 \mu \mathrm{M}, \mathrm{n}=3)\end{array}$ & $36.6 \pm 3.1$ & $62.7 \pm 6.8$ & $60.6 \pm 14.4$ & $68.8 \pm 14$ \\
\hline
\end{tabular}

Cells were held at $0 \mathrm{mV}$ and stepped to the potentials shown. Currents were measured at the end of 100 -ms voltage pulses. Percent block was determined as follows: $\left(I_{\text {control }}-I_{\text {block }}\right) / I_{\text {control }} \times 100$ for each voltage step indicated.
These experiments clearly demonstrated that the lens was able to volume regulate and that an inhibitor of $\mathrm{Cl}^{-}$channels prevented this volume regulation. We went on to investigate the ability of other $\mathrm{Cl}^{-}$channel blockers to inhibit this process and to establish that the effect was on volume regulation and not due to some other nonspecific action of the drug (Fig. 4). NPPB $(50 \mu \mathrm{M})$, which also inhibited the swelling-activated chloride channels in lens fiber cells (this study and ref. 20) was able to prevent this phenomenon of volume regulation on exposure to hypotonic solution (Fig. 4, open triangles), but neither NPPB $(50 \mu \mathrm{M})$ nor tamoxifen $(30 \mu \mathrm{M})$ had any effect

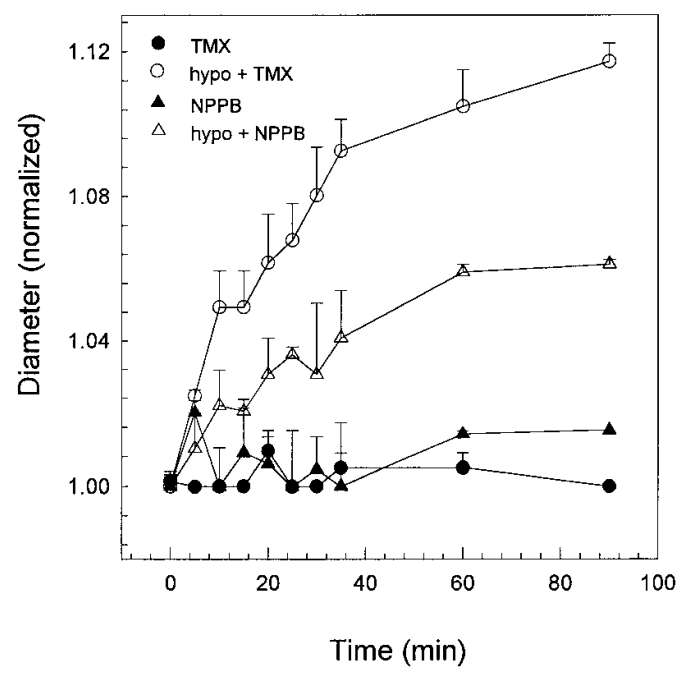

Figure 4. Lens a-p diameter in response to NPPB and tamoxifen. The effect of NPPB $(50 \mu \mathrm{M})$ and tamoxifen $(30 \mu \mathrm{M})$ alone (solid symbols) had no effect on the lens diameter over a 210-min period. In conjunction with $50 \%$ hypotonic solution, both NPPB $(50 \mu \mathrm{M})$ and tamoxifen $(30 \mu \mathrm{M})$ caused a progressive increase in lens diameter. Tamoxifen caused the greater effect. Data points are the mean $\pm \mathrm{SE}$ of three lenses in each case. Experiments were performed at room temperature in AAH (see Methods). 
A

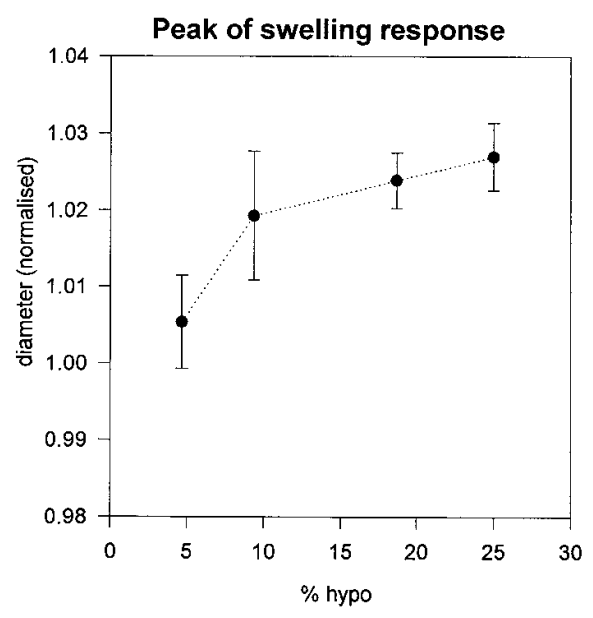

B

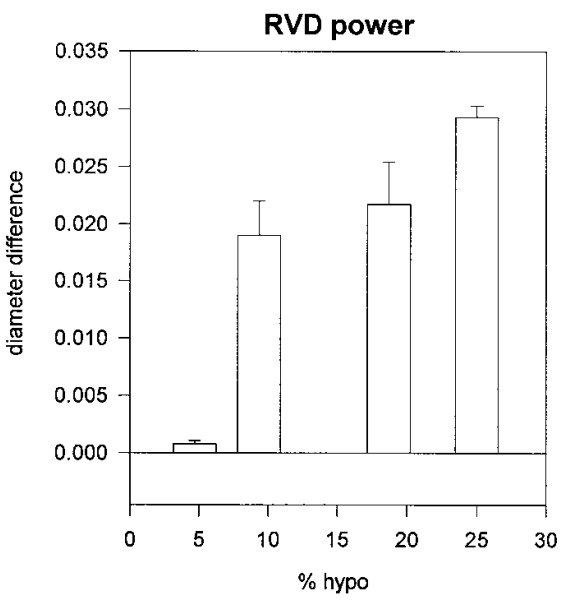

Figure 5. Degree of volume regulation. (A) Peak diameter as a function of the degree of hypotonicity. The lenses were incubated in mannitol-AAH containing $70 \mathrm{mM}$ Dmannitol (control) and in solutions containing decreasing amounts of mannitol: $58.7 \mathrm{mM}$ (4.7\% hypo), $46.7 \mathrm{mM}$ (9.4\% hypo), $23.3 \mathrm{mM}$ (18.7\% hypo), and $0 \mathrm{mM}$ ( $25 \%$ hypo). The maximum a-p diameter, reached 5-8 min after exposure to the hypotonic solution, increased with increasing hypotonic stress but in a manner suggesting that increasing stress activated regulatory mechanisms and prevented a greater increase in diameter. Each point represents the mean \pm SE of four determinations. Experiments were performed at $37^{\circ} \mathrm{C}$. (B) Degree of volume regulation. This was determined from the difference between the peak a-p diameter ( $\sim 5-8$ min; see Fig. 5

$A)$ and the minimum diameter after volume regulation $(\sim 16 \mathrm{~min})$. The increasing hypotonic stress caused an increasing degree of volume regulation. Solutions were as in Fig. $5 \mathrm{~A}$, and experiments were performed at $37^{\circ} \mathrm{C}$. Each point represents the mean $\pm \mathrm{SE}$ of four determinations.

when applied on their own without the additional challenge of hypotonic solution (Fig. 4, filled symbols).

To investigate the phenomenon of lens volume regulation further, we examined the effect of varying the degree of hypotonicity on the maximum swelling and the volume-regulatory response. For this series of experiments, mannitol-AAH (see Methods) was used, and the experiments were performed at $37^{\circ} \mathrm{C}$. The maximum swelling response, as measured by the increase in a-p diameter in four lenses, increased with increasing hypotonicity (Fig. $5 \mathrm{~A}$ ). The degree of volume regulation was measured as the maximum diameter after swelling minus the minimum diameter after volume regulation. The mean results for four lenses at four different tonicities are given in Fig. 5 B. There is a clear inverse relationship between the degree of volume regulation and the degree of hypotonicity. The lower the tonicity, the greater the volume regulation.

Both tamoxifen and NPPB prevent volume regulation when the lens is challenged with hypotonic solution, and, as we have previously shown that both of these agents cause opacification in long-term organ culture experiments (25), we asked whether the double challenge of hypotonic shock and $\mathrm{Cl}^{-}$ channel block could cause lens opacification. Fig. 6 illustrates three lenses that have been incubated for $3 \mathrm{~h}$ in control, $50 \%$ hypotonic solution, and 50\% hypotonic solution containing 30 $\mu \mathrm{M}$ tamoxifen. The lenses were uniformly illuminated by a ring lamp, and images were recorded with a digital camera. The gray scale value of each pixel could then be quantified. Beneath the gray scale images of the lenses, in which increasing opacification is represented by increasingly paler shades of gray, histograms of the gray scale value (higher value = greater opacification) for a section along a diameter of the lenses are shown. This method is sufficiently sensitive to register short-term changes. It is clear that the double challenge causes a pronounced opacification, and even the single challenge of hypotonic solution gives a significant opacification after $3 \mathrm{~h}$.

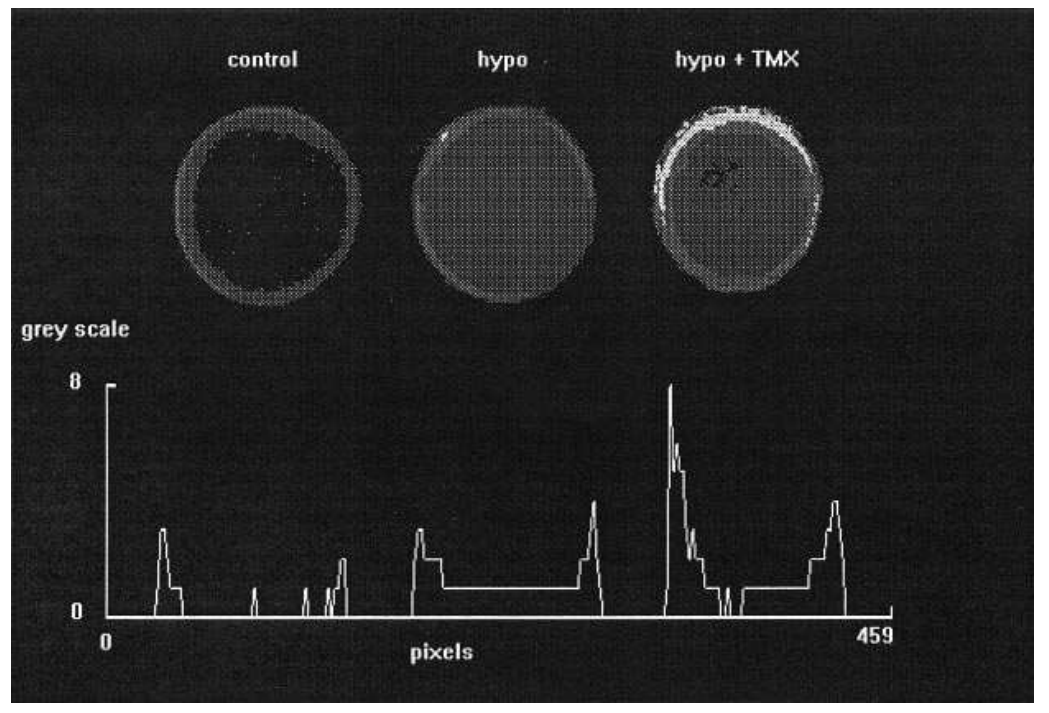

Figure 6. In vitro lens opacification. Digital images of three different lenses taken after $3 \mathrm{~h}$ in control, 50\% hypotonic solution (single challenge), and 50\% hypotonic solution + tamoxifen $(30 \mu \mathrm{M}$; double challenge). The images have been converted to 8-bit gray scale to accentuate the opacification. Below the images are gray scale intensity profiles along the diameter of each of the lenses illustrated. The higher the gray scale value, the greater the opacity. Experiments were performed at room temperature. 
While this short-term opacification cannot be directly equated with cataract, it raises the possibility that a failure in volume regulation or an excessive stress upon the volume-regulatory mechanisms in the lens could lead to opacification and cataract in the long term.

\section{Discussion}

We present several novel findings in this paper, the first of which is the ability of the lens to volume regulate in the short term. In addition, we show that fiber cells, isolated from the superficial lens cortex, possess a volume-activated $\mathrm{Cl}^{-}$channel that participates in the regulatory volume decrease. Inhibition of this channel by tamoxifen (and other chloride channel blockers) prevents volume regulation and causes the lens to swell and opacify.

The $\mathrm{Cl}^{-}$current identified in lens fiber cells exhibits outward rectification and is inhibited by NPPB and tamoxifen, characteristics consistent with the $\mathrm{Cl}^{-}$channel in lens fiber cell vesicles we reported previously (20). The present study demonstrates that the $\mathrm{Cl}^{-}$channel is activated by cell swelling. Single outwardly rectifying $\mathrm{Cl}^{-}$channels, activated by hypotonic stimulation with a conductance of $19 \mathrm{pS}$, have been observed in rabbit osteoclasts (26) under conditions similar to those of this study. In agreement with our findings, swelling-activated whole-cell currents exhibit outward rectification and are blocked by NPPB in cultured human 407 intestinal cells (27) and rat epididymal cells (28), and similar $P_{\text {gluconate }} / P_{\mathrm{Cl}}$ permeability ratios, of 0.25 and 0.17 , have been determined for volume-activated $\mathrm{Cl}^{-}$currents in HeLa cells (29) and in nonpigmented bovine ciliary epithelial cells (30), respectively, compared with 0.26 in the present study.

When exposed to hypotonic solutions, the lens was found to volume regulate. This process was inhibited by tamoxifen and NPPB, from which we can deduce that at least part of the volume regulation observed in the whole lens is accomplished by the activation of the swelling-activated $\mathrm{Cl}^{-}$channel in the fiber cells. Blockade of chloride channels is not enough on its own to cause lens swelling in the short term $(\leq 3 \mathrm{~h})$, suggesting that the channels are not involved in lens homeostasis under isotonic conditions and are only significantly activated under hypotonic conditions.

Both the lens fiber and epithelial cells possess the currents associated with volume regulation (Zhang, J.J., and T.J.C. Jacob, unpublished observations), but these alone may not be enough to account for the volume regulation observed in the whole lens. We noticed in our tamoxifen incubation experiments that a clear band appeared under the anterior capsule and epithelium as soon as $2 \mathrm{~h}$ in our hypotonic challenge experiments. This band looks like the accumulation of fluid just behind the lens epithelium and may be due to an inhibition of vectorial fluid transport (into the anterior chamber) by the epithelium. We illustrate this phenomenon in a lens cultured in the presence of tamoxifen for $3 \mathrm{~d}$ in Fig. 7. In long-term organ culture experiments, tamoxifen treatment caused opacification (see also 25), presumably because the lens is struggling to maintain homeostasis outside its normal environment and will tend to swell. The lens is thus exposed to a double challenge to its osmotic regulation.

The lens volume regulation we report in this study is an immediate and short-term response to hypotonic conditions. Whether the lens is able to respond to osmotic challenges in the long term is at present unknown and is under investigation. The lens is exposed to large osmotic fluctuations in at least two conditions. First, in diabetes mellitus the blood glucose can increase to $>40 \mathrm{mM}$, and second, in renal failure the blood urea can rise to $>100 \mathrm{mM}$. Both glucose and urea are permeant and will enter the lens, causing an osmotic swelling pressure when the plasma levels of these substances return to normal. The sustained exposure of the lens to osmotic challenges may overwhelm its capacity to volume regulate, leading to unopposed volume changes, a disruption of lens fiber cell structure, the formation of fluid-filled pockets in the extracellular space,

$$
\text { A }
$$

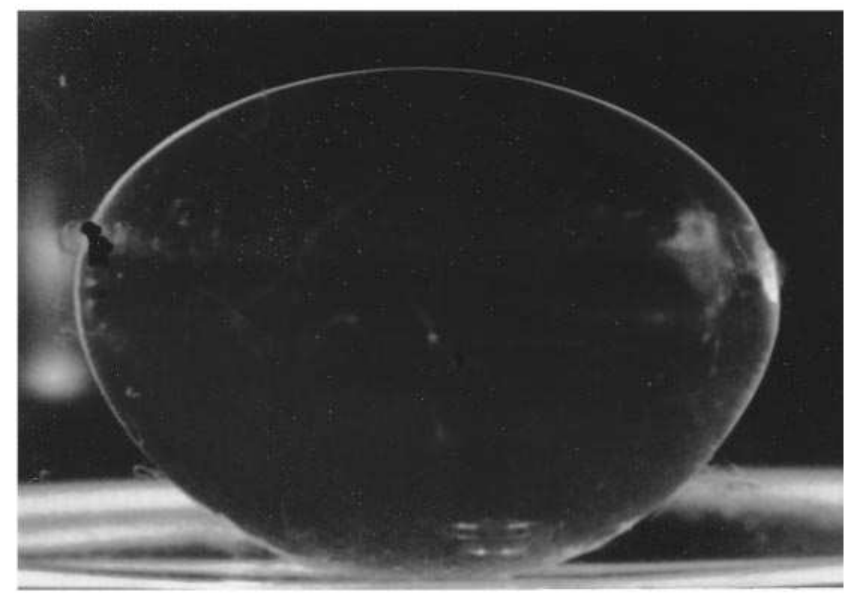

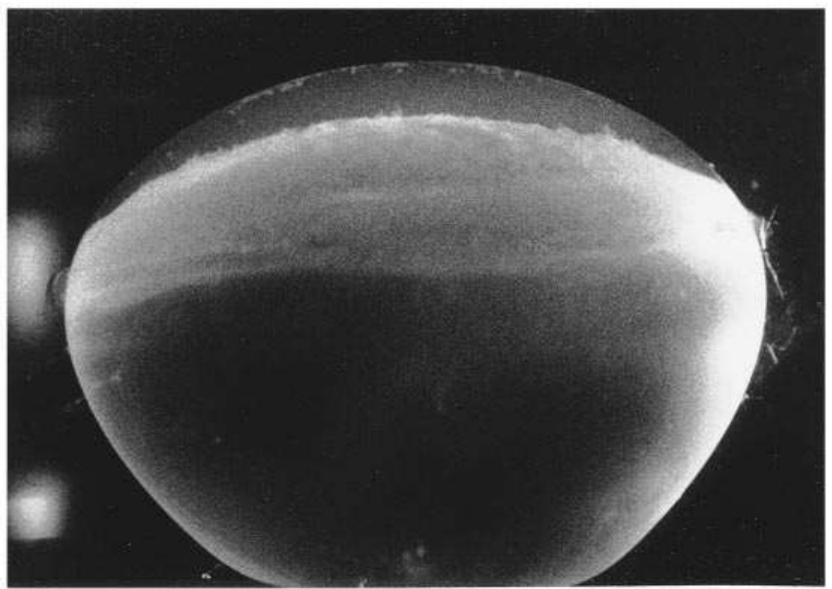

Figure 7. Lens swelling band. (A) Control lens incubated in AAH for $3 \mathrm{~d}$ under sterile conditions at $35^{\circ} \mathrm{C}$. $(B)$ Lens incubated in tamoxifen for $3 \mathrm{~d}$. Note first that the lens has become opaque, and, second, the pronounced discontinuity between the anterior epithelium (top) and the opaque region of the lens cortex. It is suggested that this band represents the accumulation of fluid behind the anterior epithelium (see text). 
and a disturbance to the hydration of the lens proteins-all of which increase light scatter and may result in protein aggregation and cataract in the long term.

It is most likely that many cataracts are multifactorial (31, 32). One factor compromises lens function but without causing cataract - or it may be subthreshold-and cataract only develops when the lens is exposed to a second challenge. This second challenge also may not cause cataract on its own but acts synergistically with the first to produce the cataract. We show that tamoxifen on its own does not cause lens swelling, at least in the short term, but acts synergistically with a hypotonic shock to cause a rapid swelling. Conversely, in hypotonic solution alone, the lens volume regulates, but when hypotonic solution and tamoxifen are combined, the lens swells and opacifies. This is of clinical significance since many women presently participate in clinical trials to test whether tamoxifen lowers the incidence of breast cancer (33). Patients on long-term prophylactic tamoxifen treatment may experience a number of occasions of "double challenge," in which their already compromised lenses are exposed to a second cataractogen (e.g., osmotic stress), possibly at levels that would be subthreshold or asymptomatic in a person not receiving tamoxifen therapy. Such patients would be particularly at risk of developing cataract. The study of such synergisms in cataractogenesis requires urgent investigation.

In summary, the superficial lens fiber cells possess a swelling-activated chloride channel that is involved with regulatory volume decrease. The whole lens has been demonstrated to regulate its volume in the short-term during exposure to hypotonic solution. Inhibitors of the swelling-activated chloride channel prevent this process of volume regulation in the whole lens and cause lens opacification.

\section{Acknowledgments}

We thank Dr. John Harding (Oxford University) for many stimulating discussions.

This work was supported by the Medical Research Council (UK), the Royal Society, and the Visual Research Trust.

\section{References}

1. Cotlier, E., B. Kwan, and C. Beaty. 1968. The lens as an osmometer and the effects of medium osmolarity on water transport, efflux, and ${ }^{86} \mathrm{Rb}$ transport by the lens. Biochim. Biophys. Acta. 150:705-722.

2. Patterson, W., and D.J. Fournier. 1976. The effect of tonicity on lens volume. Invest. \& Ophthalmol. Visual Sci. 15:866-869.

3. Duncan, G., and T.J.C. Jacob. 1984. The lens as a physicochemical system. In The Eye. Vol. 1B. H. Davson, editor. Academic Press, Orlando, FL. 159-206.

4. Jacob, T.J.C., and G. Duncan 1980. Osmotic influences on lens membrane characteristics. Exp. Eye Res. 31:505-512.

5. Maraini, G. 1991. Membrane changes in the human lens during aging and cataract formation. In Eye Lens Membranes and Aging. Topics in Aging Research in Europe. Vol. 15. G.F.J.M. Vrensen and J. Clauwaert, editors. Eurage, Leiden, The Netherlands. 45-57.

6. Duncan, G., H.R. Hightower, S.A. Gandolfi, J. Tomlinson, and G. Maraini. 1989. Human lens membrane cation permeability increases with age. Invest. Ophthalmol. \& Visual Sci. 30:1855-1859.
7. Harris, J.E., and L. Gruber. 1962. The electrolyte and water balance of the lens. Exp. Eye Res. 1:372-386.

8. Kinoshita, J.H., H.L. Kern, and L. Merola. 1961. Factors affecting the cation transport of calf lens. Biochim. Biophys. Acta. 47:458-466.

9. Korte, I., O. Hockwin, G. Cremer-Bartels, and W. Schmack. 1968. Uber die Einwiskung von ouabain auf den Stoffweschel von Rinder under Kalberlinsen. Arch. Klin. Exp. Ophthal. 175:242-246.

10. Chylack, L.T., and J.H. Kinoshita. 1969. A biochemical evaluation of a cataract induced in a high-glucose medium. Invest. Ophthalmol. \& Visual Sci. 8: 401-412.

11. Harding, J.J. 1991. Cataract: biochemistry, epidemiology and pharmacology. Chapman \& Hall, London. 167 pp.

12. Laqua, H. 1972. Katarakt bei chronischer Niereninsuffizienz und Dialysebehandlung. Klin. Mbl. Augenheilk. 160:346-350.

13. Orth, J., H.R. Koch, H.U. Klehr, and M. Siedek. 1978. Formation of hyperosmolar cataracts due to urea disequilibrium. Interdiscip. Top. Gerontol. 13: 109-117.

14. Harding, J.J. 1980. Possible causes of the unfolding of proteins in cataract and a new hypothesis to explain the high prevalence of cataract in some countries. In Ageing of the Lens. F. Regnault, O. Hockwin, and Y. Courtois, editors. Elsevier, Amsterdam. 71-80.

15. Gwinup. G., and A. Villareal. 1976. The relationship of serum glucose concentration to changes in refraction. Diabetes. 25:29-31.

16. Saito, Y., G. Ohmi, S. Kinoshita, Y. Nakamura, K. Ogawa, S. Harino, and M. Okada. 1993. Transient hyperopia with lens swelling at initial therapy in diabetes. Br. J. Ophthalmol. 77:145-148.

17. Furushima, M., M. Imaizumi, and K. Nakatsuka. 1994. Changes in refraction induced by transient hyperglycemia. Jpn. J. Clin. Ophthalmol. 48:835838

18. Loewenstein, A., Y. Almog, and M. Lazar. 1994. Loss of accommodation as the first symptom of cataract. Am. J. Ophthalmol. 117:816-817.

19. Zhang, J.J., and T.J.C. Jacob. 1993. $\mathrm{Cl}^{-}$channel block causes posterior subcapsular cataract in organ cultured bovine lenses. J. Physiol. (Camb.). 467: 108P. (Abstr.)

20. Zhang, J.J., and T.J.C. Jacob. 1994. ATP-activated chloride channels inhibited by an antibody to P-glycoprotein. Am. J. Physiol. 267:C1095-C1102.

21. Zhang, J.J., and T.J.C. Jacob. 1994. A new approach to measuring transepithelial potentials in the lens reveals a chloride-dependent component. Exp. Physiol. 79:741-753.

22. Jacob, T.J.C., and C.H. Mitchell. 1995. Chloride current activated by hypotonic shock in pigmented ciliary epithelial cells. Invest. Ophthalmol. \& Visual Sci. 36:S586. (Abstr.)

23. Wu, J., and T.J.C. Jacob. 1994. Small conductance, volume-activated chloride channels in isolated nonpigmented ciliary epithelial cells. Invest. Ophthalmol. \& Visual Sci. 35:1454. (Abstr.)

24. Valverde, M.A., G.M. Mintenig, and F.V. Sepulveda. 1993. Differential effects of tamoxifen and $\mathrm{I}^{-}$on three distinguishable chloride currents activated in T84 intestinal cells. Pflügers Arch. Eur. J. Physiol. 425:552-554.

25. Zhang, J.J., T.J.C. Jacob, M.A. Valverde, S.P. Hardy, G.M. Mintenig, F.V. Sepulveda, D.R. Gill, S.C. Hyde, A.E.O. Trezise, and C.F. Higgins. 1994 Tamoxifen blocks chloride channels. A possible mechanism for cataract formation. J. Clin. Invest. 94:1690-1697.

26. Kelly, M.E.M., S.J. Dixon, and S.M. Sims. 1994. Outwardly rectifying chloride current in rabbit osteoclasts is activated by hyposmotic stimulation. $J$. Physiol. (Camb.). 475:377-389.

27. Kubo, M., and Y. Okada. 1992. Volume-regulatory $\mathrm{Cl}^{-}$channel currents in cultured human epithelial cells. J. Physiol. (Camb.). 456:351-371.

28. Chan, H.C., W.O. Fu, Y.W. Chung, S.J. Huang, T.S. Zhou, and P.Y.D. Wong. 1993. Characterization of a swelling-induced chloride conductance in cultured rat epidydimal cells. Am. J. Physiol. 265:C997-C1005.

29. Diaz, M., M.A. Valverde, C.F. Higgins, C. Rucareanu, and F.V. Sepulveda. 1993. Volume-activated chloride channels in HeLa cells are blocked by verapamil and dideoxyforskolin. Pflügers Arch. Eur. J. Physiol. 422:347-353.

30. Wu, J., J.J. Zhang, H. Koppel, and T.J.C. Jacob. 1995. P-glycoprotein regulates a volume-activated chloride current in bovine non-pigmented ciliary epithelial cells. J. Physiol. (Camb.). 491:3.

31. Hockwin, O., and H.R. Koch. 1975. In Cataract and Abnormalities of the Lens. J.G. Bellows, editor. Grune and Stratton, New York. 243-254.

32. Schmitt, C., and O. Hockwin. 1990. The mechanisms of cataract formation. J. Inherited Metab. Dis. 13:501-508.

33. Marshall, E. 1994. Tamoxifen: hanging in the balance. Science (Wash. DC). 264:1524-1527. 